\title{
Knowledge on HIV transmission and attitude towards providing care for people living with HIV (PLHIV) and adherence to universal precautions (UP) among attendants in the National Hospital of Sri Lanka (NHSL)
}

\author{
Nanayakkara G A G ${ }^{1}$, Karawita D A ${ }^{2}$
}

\begin{abstract}
Introduction: HIV transmission knowledge, misconceptions in the society and adherence to universal precautions directly attribute to handling of PLHIV by healthcare workers.

Objectives: This study was done to assess the knowledge on HIV transmission and attitudes towards PLHIV, Knowledge on Universal Precautions and the adherence in work place among attendants working in the NHSL.

Methods: Descriptive cross sectional study was conducted among 224 randomly selected sample of health attendants. Interviewer administered questionnaire was used for data collection which included assessments of HIV transmission knowledge (score 0-10), knowledge on universal precautions (score 0-9) and attitudes towards PLHIV (score 0-8).Final scores were computed to percentage values and data were analysed using SPSS v23.
\end{abstract}

Results: Mean age of the participants was 42 years $(\mathrm{SD}=10.41)$ and majority $(66 \%)$ were married males. Most of them (60.3\%) had less than 10 years of working experience. A significant number $(65.2 \%)$ had already given care to an HIV infected patient. Mean values for "HIV transmission knowledge", "adherence to Universal precautions", and "positive attitudes for HIV care" were $84 \%, 40 \%$ and $70 \%$ respectively. Increased service duration significantly reduced both HIV transmission knowledge $(\mathrm{r}=-0.142: \mathrm{p}<0.001)$ and knowledge on universal precautions $(\mathrm{r}=-0.299$ : $\mathrm{p}<0.001)$. Furthermore, increasing age also, was negatively associated with knowledge on UP $(r=-0.393$ : $\mathrm{p}<0.001)$.

Conclusions: Knowledge on HIV transmission, and positive attitude for HIV care was over $70 \%$ but adherence to universal precautions was only $40 \%$. Increasing service duration reduce the HIV transmission knowledge and Knowledge on UP. Regular updating of knowledge regarding HIV transmission, and on UP by in-service programme should be done and special attention should be paid on the attendants in the elderly age group who have longer service duration.

Key Words: Knowledge, HIV, Attendants, attitudes, Sri Lanka

Authors: ${ }^{1}$ Dr Nanayakkara G. A. G., (MBBS, PgDip Ven, MD); Acting Venereologist, STD clinic, BH Avissawella, ${ }^{2}$ Dr Karawita D.A., (MBBS, PgDip Ven, MD, FSLCoSHH); consultant Venereologist, Teaching Hospital, Anuradhapura.

Copyright

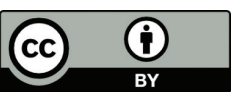

Corresponding author: ${ }^{1}$ Dr Nanayakkara G. A. G., Email: rashirasu@yahoo.com

Acknowledgement: Dr Anil Jasinghe, Director General of Health Services, former Director of National Hospital of Sri Lanka, Mrs, Madhurekha Gamage,Hospital secretary-1, National Hospital Sri Lanka, All the study participants.

Conflict of interest: No conflict of Interest

Funding: supported by Global Fund

Originality: This is an original work not published anywhere, presented at $23^{\text {rd }}$ Annual Scientific sessions of Sri Lanka College of Sexual Health and HIV Medicine, 2018

Submitted on:18.11.2018; Accepted on: 25.11.2018 


\section{Full Article}

\section{Introduction}

Cumulative reported number of HIV positive persons in Sri Lanka was 2557 by the end of December 2016 with an adult prevalence of $<0.1 \%$. (1) Sexual transmission is the predominant mode of transmission accounting for more than $90 \%$ in general, and same is true in Sri Lanka accounting for $88 \%$ of all diagnosis reported during 2016. (1) Considering the other modes of transmission, mother to child transmission can occur during pregnancy, during delivery and following delivery. Furthermore, transmission through infected blood and body fluids via accidental injuries in health care setting is important for the health care workers. Those exposures may result from needle pricks, scalpel cuts, splashes of infected material to mouth or eyes of the health care workers. The risk of transmission of HIV is $0.3 \%$ in a percutaneous injury and $0.1 \%$ in a muco-cutaneous exposure, but less than $0.1 \%$ when non- intact skin is exposed to HIV infected blood. Risk of exposure on intact skin with small amount of HIV infected blood probably poses no risk at all.(2)

Universal Precautions (UP) are recommended by the centre for disease control (CDC) to be used when providing care to all patients irrespective of their infectious status. These are the simple infection control measures which minimize the risk of transmission of blood born infections among Health Care Workers (HCW). Adherence to universal precautions by $\mathrm{HCW}$ is an important way to reduce their risk of exposure to blood and body fluids.(3)

People living with HIV/AIDS isolate themselves due to self-stigma and do not come for services including health care due to discriminative attitude of the society. Health care workers may not be free of discriminative thoughts and practices towards People Living With HIV (PLHIV) due to lack of knowledge on HIV transmission and misconceptions/misbeliefs about the disease. In the concept of continuum of care for people living with HIV/AIDS, minimizing the stigma and discriminations is a key element, which facilitate patients' entry to the health care services. It has a public health benefit as well, because, by treating PLHIV, their viral load will be reduced to undetectable levels leading to minimizing the transmission. It is obvious that the level of knowledge of HIV transmission, knowledge on Universal Precaution and adherence to universal precautions directly attribute to attendants' way of handling and caring HIV positive patients.

Hospital attendants have an assigned duty list by Director General of Health Services, ministry of health, Sri Lanka and they are bound to provide same care for the HIV positive patients without stigmatizing and discrimination.

Attendants get only three months of pre service training prior to starting the job and minimal lecture time is allocated for HIV and STI. In addition ,they are made aware about this topic by some educational programmes conducted as in-service programmes. But there may be gaps in their knowledge and it is important to asses their knowledge and attitude, which affects the outcome of care provided by them. Being the largest hospital and the ultimate tertiary care centre in the country, the National Hospital in Sri Lanka (NHSL) was selected as the study setting which provides services for all patients from Colombo district with specialized care for patients from peripheral hospitals island wide. The highest number of HIV infected patients have been reported from the Colombo district (1) results in a high chance for caring such a patient by attendants in NHSL. Having the maximum bed strength, largest number of specialist units and highest number of health care persons working in the different working areas justify the selection of the National Hospital in Sri Lanka to carry out this study.

In Sri Lanka, no studies have been carried out taking attendants as study population on this topic which justifies further to carry out this study on this important job category.

\section{Methods}

Descriptive cross sectional study was conducted among male and female attendants working in the NHSL from July 2017 to September 2017. In NHSL, attendants are working in 11 Zones out of 13 working zones, under one head overseer. A total number of 419 attendants are working in these 11 zones. Attendants who have completed training for 3 months with passing their final theory and practical assessment were included with exclusion of those who were on long leave. Simple random sampling technique was used and sampling frame was the pay roll. Sample size was calculated using 95\% confidence level, assumed proportion as $50 \%$ (0.5) and acceptable error as 5\% (0.05) using Danial (1999) formula which resulted 385. Final sample size was achieved with finite population correction 
for proportions resulting 201 and 10\% of nonresponse rate was then added and rounded off to 224. Interviewer administered data collection sheet was applied for data collection which included assessments for HIV transmission knowledge (score 0-10), knowledge on universal precautions (score 0-9) and attitudes towards PLWHIV (score 0-8), final scores were computed to percentage value and data analysis was done by using SPSS 23.0.

\section{Results}

Majority of the study participants were in the 41 to 50 years age group with age ranging from 23 years to 60 years (mean $=42.12$ years: $S D=10.41$ ). Significant number of study participants were married people. $(\mathrm{N}=174: 77 \%)$ There was a clearly identified male predominance $(66.1 \%)$ among the study participants.

Majority (92.4\%) of the study participants were working at wards and $60.3 \%(\mathrm{~N}=135)$ participants were with less than 10 years of working experience. Moreover $65 \%$ of the participants had experience of providing health care services for HIV infected patients at the time of conducting this study.

\section{Knowledge on HIV transmission}

Study participants have used 8 main sources to obtain knowledge regarding HIV transmission and gaining knowledge through health care services was the commonest method. All the participants had achieved a knowledge score above 50\%. More than $75 \%$ of the participants $(\mathrm{N}=174)$ had achieved more than $76 \%$ knowledge score and $17.9 \%(\mathrm{~N}=40)$ participants had achieved 100\% knowledge score. The mean score of knowledge regarding HIV transmission among the study participants was 83.8\% ( $\mathrm{SD}=11.5)$. A significant reduction of the knowledge among participants was $(r=-0.142$ : $\mathrm{p}<0.001)$ revealed with increased service duration.

Only 54\% ( $\mathrm{N}=121)$ participants were aware of the difference between HIV and AIDS. Clearly, 78\% were aware of reduction of HIV transmission risk by using condoms. Approximately 12\% ( $\mathrm{N}=26)$ believed that HIV transmission occurs by mosquito bites. More than $97 \%$ of the participants understood that there is a risk of transmitting HIV via blood transfusion and re -using the needles used for a HIV infected patients. Almost 20\% (N=44) believed that HIV transmission occurs through saliva, urine or sweat. Around $85 \%$ believed that HIV can be transmitted directly from mother to new born and $69.6 \%$ of them accepted that it is transmitted via breast feeding.

\section{Attitudes towards providing health care for patients with HIV/AIDS}

Attitude score of participants towards providing health care for patients with HIV or AIDS ranged from $22.2 \%$ to $100 \%$ (Mean=70.46\%: $\mathrm{SD}=17.28$ ). A significant difference of attitude levels was not identified with the gender, with the participants who had been involved in providing health care for HIV patients or with the participants who did not have the same experiences of providing care.

Table2: Distribution of attitudes of attendants towards caring of the PLHIV

\begin{tabular}{|c|c|c|c|c|}
\hline Variable & Level & $\begin{array}{l}\text { Frequency } \\
(\mathrm{N})\end{array}$ & $\begin{array}{l}\text { Percentage } \\
(\%)\end{array}$ & $\begin{array}{l}\text { Central } \\
\text { tendency/ } \\
\text { dispersion }\end{array}$ \\
\hline \multirow{5}{*}{$\begin{array}{l}\text { Attitude } \\
\text { Score }\end{array}$} & $<25 \%$ & 5 & 2.2 & \multirow{5}{*}{$\begin{array}{l}\text { Mean }=70.46 \\
S D=17.28\end{array}$} \\
\hline & $26-50$ & 24 & 10.7 & \\
\hline & $51-75$ & 77 & 34.4 & \\
\hline & $>76 \%$ & 118 & 52.7 & \\
\hline & Total & 224 & 100 & \\
\hline
\end{tabular}

Majority (91\%) of the study participants were having an attitude that health care workers should be aware of the positivity of the HIV patient, but majority did not think that identity of HIV patients should be documented in that their Bed Head Tickets. Majority (83\%) agreed that HIV patients should not be kept isolated from other patients and $70 \%$ accepted the patient right of securing the confidentiality regarding their HIV status. Majority were in a satisfactory attitude that there is no need of destroying the materials used by HIV patients.

\section{Knowledge and adherence to universal precautions}

The knowledge score on UP obtained in the study ranged from $22 \%$ to $100 \%$ (Mean $64.8 \%$ : $\mathrm{SD}=18.5)$. Out of all, $4.5 \%$ of the study participants $(\mathrm{N}=10)$ had achieved a $100 \%$ score .A significantly negative association was observed between the knowledge score and the service duration and the age of the participants $(r=-0.393: p<0.001$ and $r=$ $-0.299: \mathrm{p}<0.001)$.

Only $40.2 \% \quad(\mathrm{~N}=90)$ of the participants always adhered to the standard and recommended universal precaution strategies. A significant number of participants $(59 \%)$ with a service duration more than 10 years demonstrated a practice of strict adherence to the universal precautions ( $\mathrm{OR}=1.495)$. 
Table1: Distribution of pattern of knowledge among participants $(\mathbf{n}=224)$

\begin{tabular}{|c|c|c|c|c|}
\hline Variable label & $\begin{array}{l}\text { Yes } \\
\text { Number } \\
(\%)\end{array}$ & $\begin{array}{l}\text { No } \\
\text { Number } \\
(\%)\end{array}$ & $\begin{array}{l}\text { Don't } \\
\text { Know } \\
\text { Number } \\
(\%)\end{array}$ & Total \\
\hline Is there a difference between HIV and AIDS? & $121(54)$ & $94(42)$ & $9(4)$ & $224(100)$ \\
\hline $\begin{array}{l}\text { Can HIV be transmitted from an infected partner to his/her non- } \\
\text { infected partner during sexual intercourse? }\end{array}$ & $221(98.7)$ & $3(1.3)$ & - & $224(100)$ \\
\hline $\begin{array}{l}\text { Can a person reduce the risk of getting HIV by using a condom } \\
\text { correctly every time they have sex? }\end{array}$ & $176(78.6)$ & $39(17.4)$ & $9(4)$ & $224(100)$ \\
\hline Can a healthy looking person have HIV? & $219(97.8)$ & $4(1.8)$ & $1(0.8)$ & $224(100)$ \\
\hline Can a person get HIV from mosquito bites? & $26(11.6)$ & $184(82.1)$ & $14(6.3)$ & $224(100)$ \\
\hline $\begin{array}{l}\text { Can a person get HIV from a blood transfusion of a HIV infected } \\
\text { blood/blood products? }\end{array}$ & $218(97.3)$ & $6(2.7)$ & - & $224(100)$ \\
\hline $\begin{array}{l}\text { Can a person get HIV by getting injections from a needle already } \\
\text { used by a HIV positive patient? }\end{array}$ & $222(99.1)$ & $2(0.9)$ & - & $224(100)$ \\
\hline $\begin{array}{l}\text { Can HIV pass through saliva, urine and sweat of infected patients? } \\
\text { (not contaminated with blood) }\end{array}$ & $44(19.6)$ & $169(75.4)$ & $11(4.9)$ & $224(100)$ \\
\hline Can a woman who has HIV pass on the disease to her unborn child? & $192(85.7)$ & $24(10.7)$ & $8(3.6)$ & $224(100)$ \\
\hline $\begin{array}{l}\text { Can a HIV infected mother transmit HIV to the baby by breast } \\
\text { feeding? }\end{array}$ & $156(69.6)$ & $51(22.8)$ & $17(7.6)$ & $224(100)$ \\
\hline
\end{tabular}

\section{Discussion}

Knowledge regarding HIV transmission among study participants was found to be in an advanced standard. A knowledge score of more than $76 \%$ was achieved by $77.7 \%$ of the study participants. All the study participants had achieved more than 50\% knowledge score regarding HIV transmission. A $100 \%$ knowledge score was achieved by $1 / 5$ of the present study sample. According to the study conducted in 2012 by Ranathunga et al, knowledge regarding HIV transmission among the primary health care workers was as high as $80 \%$.(4) In the present study, majority has rejected misconceptions on HIV transmission sensibly. Only $45 \%$ of the health care workers in a study done in Pakistan, which is a neighbouring South Asian country had correct knowledge regarding HIV transmission.(5) In an Italian study, which is considered as a developed country, nurses had some misconceptions on HIV. According to that study, attendants' knowledge regarding HIV transmission was more acceptable than the knowledge of nursing officers.(6)

In the present study, attitudes of patient care among the HCW was in a satisfactory level (Mean score $70.46 \%$; Range $22 \%-100 \%$ ). But a considerable proportion (12.9\%) had an attitude score less than
$50 \%$. Among them, five $(2.2 \%)$ reported an attitude score less than $25 \%$.In the study done among Italian nurses, $97 \%$ elicited positive attitudes for accepting HIV infected patients to health institutions for treatment.(6) In the present study, $98.2 \%$ of the attendants were in an opinion that they cannot refuse treating patients with a view of protecting themselves. In Bangladesh , $47.9 \%$ of health care workers were in an opinion that HIV infected patients should not be mixed with other patients. (7) But in the present study, only $14.7 \%$ carried the same opinion. In the present study majority of the participants believed that, the health care worker should be informed regarding the HIV positivity of the patients before providing care. This attitude indirectly expresses their fear. However, minimum number of participants were $(1.8 \%)$ in a view of refusing provision of care. In Nigeria, which is an African country with a high prevalence of HIV patients, discriminatory attitudes were observed in a notably higher level.(8) Findings on discriminatory attitudes towards patients with HIV, vary from a study to another as it depends on the educational level, intelligence level and the socio economic background of the health care worker.

In the present study the mean knowledge score on UP was relatively high as $64.8 \%$. Significant 
negative correlation of knowledge score was observed between the service duration and age of the participants. A multi-site study done in United Kingdom confirmed that only $10 \%$ of the health care workers adhere to the universal precautions during all the care giving hours and in the United States of America this percentage was $17.4 \%$.(9) In the present study sample, situation is more satisfactory than the above mentioned developed countries .

It is expected that, longer the service duration, adherence to the universal precautions is more. But the important point is, score obtained on the knowledge about universal precautions and service duration shows a negative correlation. Therefore "adhering to the practices do not depend on the knowledge about universal precautions", does not appear accurate or satisfactory. This should be especially considered during in service training programmes.

\section{Conclusions and Recommendations}

Knowledge regarding HIV transmission among study participants was found to be high but it is important to pay more attention to the fact that, this knowledge should be updated frequently. Knowledge on HIV transmission negatively correlated with the participants' age and the service duration, therefore further researches should be conducted to identify reasons for this relationship. Regular updating of knowledge regarding HIV transmission by inservice training programmes should be done with a special attention to the attendants in the elderly age groups who have longer service duration.

A significant majority of the attendants has positive attitudes towards providing health care facilities to HIV patients but periodical attitude changing activities should be conducted in order to minimize the impact that would cause by the few study participants with negative attitudes.

An average knowledge score is demonstrated among the study participants regarding universal precautions. It also negatively correlates with the service duration and the age of the participants.

Adherence to universal precautions at all times is relatively less among the study participants and the participants with a longer service duration were adhering to the universal precautions more. Therefore, knowledge regarding universal precautions among study participants should be updated and adherence to the universal precautions should be closely observed.

\section{References}

1. National STD/AIDS Control Programme. Annual Report 2016. Colombo: Ministry of Health, National STD/AIDS Control Programme; 2016.

2. CDC. Exposure to Blood, What Health care personnel need to know. Atlanta: Centre of Disease Control, Department of Health and Human Services; 2003.

3. WHO. Prevention of transmission through blood. In National AIDS Programme Management. Geneva: WHO; 2007. p. module 6 sub module 6.6.

4. Ranatunga J, Somawardhana H. Azraan A. Integration of SRH/STI/HIV services; Baseline assessment of knowledge in primary healthcare workers. Sri Lanka Journal of Venereology. 2013; 3(1): p. 38-40.

5. Mohsin Saeed Khan, Magnus Unemo, Shakila Zaman, Cecilia S. Knowledge, Attitudes and Practices Regarding human Immunodeficiency Virus/Acquired Immune Deficiency Syndrome and Sexually transmitted Infections Among Health Care Providers in Lahore, Pakistan. J Ayub Med Coll Abbottabad. 2009; 21(4).

6. Marina Marranzano, Rosalia Ragusa, Marco Platania, Giuseppina Faro, Maria Anna Coniglio. Knowledge, attitudes and practices towards patients with HIV/ AIDS in staff nurses in one university hospital in Sicily Epidemiology Biostatistics and. Epidemiology Biostatistics and Public Health. 2013; 10(1).

7. Mohammad Bellal Hossain1 and Susan Kippax. HIVrelated Discriminatory Attitudes of Healthcare Workers in Bangladesh- J HEALTH POPUL NUTR 2010 Apr;28(2):199-207. J Health Popul Nutr. 2010 Apri; 28(2): p. 199-207.

8. Chen Reis, Michele Heisler, Lynn L. Amowitz, R. Scott Moreland, Je. Discriminatory Attitudes and Practices by Health Workers toward Patients with HIV/AIDS in Nigeria. PLoS Medicine. 2005 August; 2(8): p. 246.

9. Donna Power, Donna Amellino,Mary Dolansky, Joyce Fitzpatric. Factors influencing nurse compliance with Standard precautions. American Journal of Infection Control. 2016 January; 44(1): p. 4-7. 